\title{
The Simplification Domestic Violence in Colleen Hoover's It Ends with Us (2016)
}

\author{
$1^{\text {st }}$ Winda Dwiastuti \\ English Studies Program, Faculty of \\ Humanities \\ Universitas Indonesia \\ Depok, Indonesia \\ winda.dwiastuti51@ui.ac.id
}

\author{
$2^{\text {nd }}$ Harumi Manik Ayu Yamin* \\ Linguistics Department, Faculty of \\ Humanities \\ Universitas Indonesia \\ Depok, Indonesia \\ harumi.m@ui.ac.id
}

\begin{abstract}
Many popular culture genres have tried to address the issue of domestic violence, attempting to raise awareness, and empower people who experience violence in their relationships. However, domestic violence is a complex issue and is often misrepresented. Thus, critical appraisals of how popular cultural productions portray domestic violence are urgently required. To this end, the present article utilizes the qualitative research method of close textual reading to examine the peripheral characters of the novel, It Ends with $U s$ (2016). The analysis evaluates the attitudes of these characters toward others and scrutinizes their reactions to the issue of domestic violence. The examination is grounded in theories such as Flood, Pease, Taylor, and Webster's (2009) concept of attitudes and Schippers' (2007) notion of hegemonic femininity. The findings of this study indicate that the majority of the characters in the novel exemplify a simplified perspective of domestic violence and tend to regard violence as a private and normal phenomenon in a marriage. The outcomes of the study also indicate that the attitudes of these characters toward domestic violence are influenced by several factors such as internalized patriarchal norms and perspectives on marriage. In conclusion, the peripheral characters of the novel fail to function maximally to support the abused female protagonist. The novel's proposed solution to the issue of domestic violence is also overly simple: it does not propose professional intervention or punitive measures against the abuser.
\end{abstract}

Keywords - attitudes, character analysis, domestic violence, It Ends with Us

\section{Introduction}

"Loving someone and hurting someone aren't mutually exclusive," Christina [1] asserts in her review of Colleen Hoover's novel, It Ends with Us [2]. The intermingling of love and violence in the form of domestic violence has been a long-standing global issue [3]. Consequently, numerous attempts have been made on varied platforms including popular culture to initiate dialog on this problem. Colleen Hoover is one among many novelists to address the issue of domestic violence in fiction. In this novel, Hoover approaches the problem of relational violence through the life story of her female protagonist, Lily Bloom. Lily is already acquainted with this dark side of love having witnessed her mother's abuse at the hands of her father when she was a child. Yet, Lily falls into the same trap when her lover and later her husband, Ryle Kincaid, hurts her like her father did her mother. The novel became a bestseller soon after its publication in 2016 and left a lasting impression on many readers. It was also awarded the Best Romance
Goodreads Choice Award only four months after its release in 2016 [4]. Many reviewers praised the book for its ability to empower other people who also live in abusive relationships. Some critics also claimed that Hoover's novel delivered a "raw and honest portrayal" [5] of domestic violence.

Several recent research projects on domestic violence have analyzed societal attitudes toward the issue. These studies found the influence of several factors in the social acceptance of domestic violence. Some of these dynamics include religious and patriarchal beliefs, romantic and trivializing media portrayals of domestic violence, and an individual's historical context of living with abusive behavior or past exposure to domestic violence [6], [7]. Experts in this field emphasize the importance of friends and family in helping victims who suffer abuse at the hands of those closest to them in relational terms [8]. According to Parker [8], scant research has been conducted on the role played by informal networks in domestic abuse situations. The extant research has found, however, that when adequate support is extended from family members and friends, an improvement can be observed in the quality of life of abuse victims, who then become motivated to seek appropriate help from professionals. However, novels about domestic violence rarely explore these informal networks of support. The extant research on domestic violence in literature has largely focused on the analysis of the following aspects: factors that influence women to leave their abusers, how women deal with domestic violence [9], and how domestic violence is romanticized through the characterization of the male abuser [10].

This paper contributes to the body of scholarly investigation accomplished on the description of informal networks of support in literature. To this end, it utilizes $I t$ Ends with $U s$ as its corpus and attends specifically to the attitudes evinced by the characters who form the victimprotagonist's informal relational network toward her situation. The novel seems to empower those who suffer domestic abuse because the female protagonist is able to end her cycle of abuse. However, when the focus shifts to the informal networks around her, this novel appears to simplify the extremely complex and nuanced problem of domestic violence. This reductionism is crucial because inaccuracies in depicting domestic abuse in popular culture can potentially affect the general public understanding of the issue. Popular culture exercises immense influence over the lives of people. Diane Shoos, the author of Domestic Violence in Hollywood Film (2017), is reported by Sidortsova [11] to confirm that "all cultural representations 
will have an influence on us." Thus, the present analysis of the plot and the attitudes of the peripheral characters of $I t$ Ends with Us toward domestic violence asks and attempts to answer the following research questions: How do the peripheral characters of the novel perceive the issue of domestic violence? How do these characters provide help to the abused woman? Does the "society" depicted in the novel construct a positive support system that helps the abused woman end the cycle of abuse?

\section{Method}

This study applies the qualitative methodology in the form of a close textual reading of the novel and seeks to divulge the ways in which the abused woman's informal network of relationships perceives domestic violence. The attitudes held by those who form the protagonist's support system are analyzed using Flood et al.'s [12] concept of attitude as the main theoretical framework of this study. According to Flood et al. [12], attitudes significantly impact violence against women and influence "community and institutional responses to violence against women, the perpetration of violence against women, and women's responses to this victimization." In referring to the informal networks in the novel, this paper uses Nurgiyantoro's [14] definition of peripheral characters. According to him, the principal function of peripheral characters is to complete and support the main character. However, they can also exert their own influence, to a certain degree, on the overall plot development [14].

\section{Results and Discussion}

\section{A. The Perspectives and Responses of the Female Peripheral Characters to Domestic Violence}

The novel presents two peripheral female characters who are close to Lily, Allysa Kincaid and Jenny Bloom. Flood et al.'s [12] concept of attitude and Schippers' [15] concept of hegemonic femininity is referenced in this section to analyze how these characters respond to domestic violence. It has been argued that "Attitudes play a role in how individuals other than the perpetrator or victim interpret and respond to violence against women." The attitudes are themselves also determined by several factors such as social norms, communal attitudes toward gender, and the influence of peers and colleagues [12].

Even though Allysa and Jenny exist in the novel as Lily's support system, both characters tender ambivalent responses to her experience with domestic violence. Allysa is the younger sister of the abuser, Ryle Kincaid, and the best friend of the abused, Lily Bloom. These conflicting roles shape her ambivalent responses to the conflict between Lily and Ryle to a large extent, both in terms of her reactions and in the way she helps Lily. As Lily's friend, she wants to warn Lily about her brother's abusive personality. However, her position as the subordinate in the family and her filial love prevent her from warning Lily about the potential danger posed to her by Ryle. Readers can detect through Lily's narrative voice the ambivalence in Allysa's response when she sees Lily's bruises after the second incident of abuse has occurred.
“"Ryle,' Allysa whispers. "What did you do to her?" She walks around the counter and pulls me in for a hug. (...) She pulls back with tears in her eyes, and her reaction confuses me. She obviously knows Ryle is responsible, but if that's the case, it seems she would be attacking him, or at least yelling." (p.237)

In this instance, Allysa demonstrates her concern for Lily's wellbeing, but what is absent from her reaction is a condemnation of her brother's violent behavior or any feelings of resentment toward Ryle for hurting Lily. After she learns about the fight, she wants Lily to know instead about her brother's traumatic past involving the death of their older brother, Emerson Kincaid. Even though Allysa does not ask Lily to forgive Ryle, she justifies Ryle's acts of violence in a way by mentioning his childhood trauma. As a result, Lily is convinced to give Ryle another chance because she is convinced that Ryle can change and that he is still essentially a kind man. Allysa embodies what is defined by Schippers [15] as hegemonic femininity: womanly characteristics that facilitate her subordination as a sister and that sustain the domination of her brother.

Next, Lily's mother, Jenny Bloom, is the last person to know of the abuse Lily has experienced. As cited in Fernandez (2006) [16], Boonzainer and De la Rey (2003) [17] argue that women's responses toward domestic violence are linked to several aspects: their sense of self, gendered views of the world, and attitudes toward marriage. Jenny Bloom's beliefs about gender roles and married life have been shaped by her abusive relationship with her own husband. She perceives home and family as sacred and she wants to provide her daughter a home. Therefore, she decides to stay in the abusive household and endures her husband's violent attitude toward her until he dies from cancer. Her beliefs about the sanctity of marriage also drive her to do everything she can to prevent outsiders from learning about her husband's violence against her. Jenny's attitudes surface in Lily's case too, and they become apparent when she asks Lily to lie to the people at the hospital about the cause of her injuries. "...tell them you slipped on the ice." (p.110). Jenny's actions stem from her fear that people will judge, blame, and stigmatize her daughter [12].

The manner in which Jenny and Allysa help and advise Lily reveals that they regard domestic abuse to be a problem that will end after the abused leaves her abuser. When Lily first decides to tell Allysa about the abuse, Allysa's response is, "As his sister, I wish more than anything that you could find a way to forgive him. But as your best friend, I have to tell you that if you take him back, I will never speak to you again" (p.315). From this excerpt, it can be inferred that Allysa's conflicted position also affects the way she proposes solutions to Lily's problem. Next, when Lily tells Jenny everything, Jenny also advises Lily implicitly to leave Ryle for good, "Every time you choose to stay, it makes the next time that much harder to leave. Eventually, you lose sight of your limit altogether, because you started to think, 'I've lasted five years now, what's five more?' (...) Don't be like me, Lily." (p.335) She speaks from her own experience. However, all her internalized beliefs about 
women and their roles constrict her from truly helping Lily in finding a proper solution to her problem. In this case, Jenny can only offer Lily her emotional support.

The perspectives of both the supporting female characters on how Lily should end the abusive relationship are facile. Their dialogs imply that leaving the abuser is enough action. Okun (1986) [19] is cited in Yamawaki, Ochoa-Shipp, Pulsipher, Harlos, and Swindler [18] to describe the general public's simplified perspective on domestic violence as a lack of understanding about the immense actual complexity of the issue of domestic violence. In this instance, Lily's family members and the people closest to her, Allysa and Jenny, do not actively help Lily to deal with the abuse. They do not help Lily to critically assess her situation or assist her in finding a safe haven away from Ryle. They also never attempt to persuade Lily to report Ryle to the police. In fact, ending the cycle of abuse is not a simple matter. In an article written by Filipovic [20], Michelle Kaminsky, the chief of the Domestic Violence Bureau of the District Attorney's Office, elucidates the many factors a woman must consider before leaving her abuser: her financial stability, childcare, and her own psychological state [20]. Many women can leave their abuser only after they use their agency and resources to employ "strategic life choices" [21], [22]. It is evident that the family members and friends play pivotal roles in the victims of domestic abuse, providing them with the resources and the emotional support they require [20].

In the novel, Lily learns a lot just by living in proximity to Jenny and Allysa. In turn, these life lessons help her to make her final decision. She learns from Allysa how to see the positives in her situation and how to cherish her unborn baby. Lily also realizes that unlike her own mother, she has been accorded many privileges in the form of financial stability and other resources. These advantages allow her to leave Ryle. Lily's discussion with Jenny also presents her with the opportunity to learn from Jenny's experiences with domestic violence and apply that learning to her own situation.

\section{B. The Perspectives and Responses of the Male Peripheral Characters to Domestic Violence}

\section{- Atlas Corrigan}

Atlas is Lily's first love and the person who knows Lily's history with domestic violence firsthand. In the novel, he is willing to help Lily end her cycle of abuse. However, the plot simplifies the notion of domestic violence as a serious issue by portraying Lily as the sole decision-maker and downplays Atlas' potential of actively helping Lily end her cycle of abuse. Throughout the novel, Atlas demonstrates a strict no-tolerance policy toward violence against women, and his perspective is shaped by several factors such as his nature, his past experiences with domestic violence, his ability to cope with adversity, and his age. Just like Lily, Atlas has experienced domestic violence in the past, suffering severe abuse at the hands of his stepfather in his childhood. Despite-or perhaps because of-Atlas' traumatic growth years, he develops an absolute intolerance to violence against women. He proves this intransigence through his actions when he comes to know that Lily is being abused by Ryle: "Atlas lunges for Ryle again, this time shoving his forearm against Ryle's throat, pinning him against the wall. 'You touch her again and I'll cut your fucking hand off and shove it down your throat"" (p.198). One of the possible reasons for his uncompromising attitude to violence could be that he does not stay for too long within his abusive childhood household: he is thrown out by his stepfather shortly after his mother remarries. Thereafter, Atlas must strive hard to survive on his own. Atlas' character is congruent with Kaufman and Zigler's (1993) [23] report that the majority of the people who are abused as children do not grow up to themselves become abusive as adults [24].

Filipovic [20] emphasizes the importance of friends and family members in helping abused women end the cycle of abuse. According to Flood et al. [13], "women living with intimate partner violence are more likely to turn to friends and family than to the police or other professionals' networks." Victims of domestic violence often feel reluctant to disclose the abuse for varying reasons. In Lily's case, they are the "complicated emotional reasons and fear [of] the implications of disclosure" [8]. Lily is afraid that people will judge her or advise her to stay with her husband if they become aware that she is abused. Informal networks of friends and family members should assist abused women by functioning as a bridge between the victims and the experts [8]. However, this novel reduces the nuanced issues of domestic violence by dismissing Atlas' potential ability to help Lily and by placing the onus of resolving the problem solidly on Lily's own shoulders. First, Atlas does not act in any significant way to help Lily at instances when Jenny is abused because of various reasons: Lily's lies about what has really happened, or Jenny refuses to report her husband to the police. Lily's decision to lie may have stemmed from her distrust of other people, especially men, since the only male figure she has intimately witnessed before meeting Atlas is her father (p.148). Second, the novel portrays Lily as the primary decision-maker in dealing with her abuse-whether it is to reject assistance or to ask for help-and in ending her relationship with Ryle. Atlas' actions and suggestions are always rejected by Lily unless she is the one who asks for his help. This reluctance on Lily's part may be attributed to her state of denial that Ryle could abuse her.

\section{- Andrew Bloom}

Flood et al.'s [12] concept of attitude is appropriate for the examination of Andrew Bloom's attitude to the issue of domestic violence in the novel and how his character affects Lily's decision-making. Lily's father Andrew Bloom is portrayed as a successful and respected man: he is the town's mayor as well as the owner of a thriving real-estate agency. However, not many people know that he is abusive to his wife. Flood et al. [12] explain that a person's attitude and situational factors play a major part in the perpetration of violence. As an abuser, Andrew's attitude toward domestic violence is shaped by several factors such as internalized patriarchal values, traditional gender roles, and his own violent nature, which is often triggered by alcohol and jealousy 
with regard to Jenny. Andrew is the one who wields control and power in his household and he does not hesitate to exercise this authority over Jenny by using violence and sexual aggression if he perceives that Jenny has failed to behave according to his desires or if he thinks she shows signs of infidelity. Andrew Bloom's nature is revealed to the reader in chapter 11.

It sounded like my father was accusing her of flirting with some man. (...) I heard him call her a whore and then I heard the first blow. (...) They were on the couch and he had his hand around her throat, but his other hand was pulling up her dress. (...) She kept begging him to get off her and then he hit her right across the face and told her to shut up. (pp.153-154)

Later, Jenny confirms that Andrew was also drunk when he abused her. In his inebriated state, he accused Jenny of infidelity and used his suspicions as his excuse to force himself on her. Andrew's actions validate Flood et al.'s [12] clarification that people often justify wifebeating by asserting that "they suspected infidelity by wives or their disobedience toward a husband." Andrew Bloom dies of cancer by the time Lily marries Ryle. However, Lily's experiences, both as a witness to her father's abusive acts and a direct victim of Ryle's violence, allow her to learn hard lessons from her parents' marriage.

\section{- Brad and Darin}

Flood et al. [12] elucidate that the attitudes of people toward violence against women are influenced by several factors. These variables include common social norms that prevail in communities, peer groups, professions, and the collective mindset about gender. The interactions between characters reveal that Brad and Darin demonstrate reductionist and facile perspectives on domestic violence. Lily meets Brad and Darin at Atlas' house after Ryle perpetrates a violent act on her for the third time. Curious about Brad and Darin's opinion, she tells them about what she has suffered, "We got into a fight two nights ago and he head-butted me. Atlas took me to the emergency room. They gave me six stitches and told me I was pregnant." (p.297) Brad and Darin's simplified view toward intimate partner violence is visible from the way they make light of the situation through comments and jokes. Brad's first response is "You should get some Rodan and Fields. The amp roller works wonders for scarring." (p.297). Some studies have analyzed how intimate partner violence is normalized in societies and using comedic portrayals is one way in which such normalization takes place. Kohlman et al. [7] argue that people often use humor to downplay domestic violence and Brad, as quoted in the previous excerpt, exemplifies this tactic. First, Rodan and Fields [28], is an American skincare brand. Their products, including the "amp roller," cannot be used to cure severe scars and bruises since they are meant to brighten and smoothen skin tones. Next, Brad's view of domestic violence as a simple issue is also reflected in his follow-up comment. "The stuff works. You'd know that if you'd use it on your damn acne." (p.297). The manner in which he trivializes the severity of six stitches, scars, and bruises by trying to equate them with acnes reflects the general social acceptance of domestic violence. Brad's responses also imply that he believes violence to be a normal occurrence in a marriage. Lily's use of the words "headbutted," "emergency room," and "six stitches" clearly implies the severe violence that was inflicted by her husband. However, despite the very evident gravity of the situation, Brad asks Lily to "Relax." He goes on to say, "Me and Lily are tight, she knows I'm kidding." (...) "Your life might be complete crap right now, Lily, but it'll get better. Trust me, I've been there" (p.300). Brad implies that he believes that everything happening to Lily - the fight, the violence, and the scars-is a common and accepted phenomenon in marital life. Brad's response toward domestic violence corresponds to Kohlman et al.'s [7] findings of the normalization of domestic violence. A society's interpretation of marriage results in implications that induce the communal acceptance of domestic violence.

Darin's way of responding to Brad's random comment shows that he participates in downplaying violence in marriage. Darin's immediate reaction to Brad's comments is described as "Darin laughs. 'You've been beat up and pregnant and hiding out at another man's house?"' (p.300). The significance of the issue is downplayed when Darin laughs at Brad's comment, and the effect of his assertion is that violence in marriage seems "acceptable as a means of controlling women" [25]. The attitudes of both these peripheral male characters to domestic violence may also be influenced by their occupations. Flood et al. [13] explicate that people's attitudes toward domestic violence are also influenced by their professions. Darin introduces himself as the sous chef at Bib's and Brad is a dishwasher. Unlike people involved in social or medical domains such as social workers or medical personnel who would probably espouse a more intolerant view toward domestic violence because of their contextual awareness of the issue, bluecollar workers such as sous chefs and dishwashers could be less exposed or sensitized to the problems posed by domestic violence. Perhaps his professional and socioeconomic limitations cause Brad to bluntly say to his friend Jimmy that Lily is a woman who is "married to an asshole and just found out she's pregnant with the asshole's baby." (p.298).

\section{- Marshall}

Marshall is Allysa's husband and Ryle's best friend. In the novel, we see how the two friends are often engaged in male bonding activities such as going to the bar or watching sports matches together. Hammarén \& Johansson [26] call this kind of horizontal homosociality a "bromance," a term which indicates "close and intimate non-sexual and homosexual relationship between two (or more) men." The strong bond between the two men and Marshall and Allysa's admiration for Ryle can also be seen in the couple's decision to name their daughter after Ryle. However, Marshall's bromance with Ryle greatly affects the way he responds to the issue of domestic violence, and the way he extends his help to Lily. Despite his promise to Lily and Allysa that no one would come to know about Lily's pregnancy, he breaks his promise easily because of his relationship with Ryle. 
"Look." He (Ryle) steps aside and my eyes fall to someone standing behind him. Now I'm the one who feels betrayed. "Marshall?" Marshall immediately holds up his hands in defense. "I had no idea he was coming home early, Lily. Ryle texted and asked for my help. He specifically told me not to say anything to you or Issa. Please don't let her divorce me, I'm simply an innocent bystander." (p.320)

Marshall's actions demonstrate the manner in which social circles can influence people's attitudes toward domestic violence [27]. His actions before and after Ryle's request are contradictory. By breaking his promise to Allysa and Lily, and by helping Ryle meet Lily without first seeking her consent, Marshall shows that relations between men can overpower men's relations with women [27]. Throughout the novel, Marshall's actions and words demonstrate that he views domestic violence as a private matter between two people. His defensive hand gestures and his statement about being "simply an innocent bystander" clearly highlight his desire not to be involved in what he considers a matter that should be kept within the confines of Lily and Ryle's lives.

\section{Conclusions}

In conclusion, despite the popular opinion of readers which claim that It Ends with $U s$ is an empowering narrative, the issue of domestic violence discussed in the novel is simplified through its plot and through the perspectives of the peripheral characters as demonstrated by their varied responses to the abuse Lily undergoes in her marriage. The narrow viewpoint of the public and the and lack of a layered understanding of the complexity of domestic violence is influenced by myriad factors such as self-conception, internalized patriarchal norms, traditional gender roles, social perspectives on marriage, occupations, and homosocial bonds with peers. The significance of the psychosocial issue of relational violence is also reduced by the way in which it is resolved in the plot of this novel. Jenny and Allysa claim repeatedly that the problem will be settled once Lily leaves her abuser, Ryle. Next, the novel places the onus of the resolution of her problem squarely on Lily, who is shown as the primary decision-maker in confronting domestic violence. Besides Atlas, the other peripheral characters do not provide Lily with any concrete suggestions or real assistance. Thus, "the society," as it is represented by the people around Lily, does not function maximally as a positive system of support to her in her time of need. This failure to extend real help stems from the limited understanding of the peripheral characters with regard to domestic violence. Lily's support network of friends and family members is not even privy to all her decisions. By the end of the novel, Lily is able to leave her abusive relationship. She manages to discuss her future with Ryle and makes him understand that separating is the best solution. However, the solution of divorce seems too facile a resolution for the grave transgression of battering a woman within the institution of marriage. The abuser is left unpunished and is left free to potentially abuse other women in the future. The book seems to suggest that leaving one's abuser is enough. However, domestic violence is an insidiously intricate problem, and proper representation of this psychosocial evil is mandatory because inaccuracies in depicting this issue in popular literary genres such as romances could influence the wider understanding of the problem. Popular culture exists in various forms and people consume it to obtain information as well as entertainment. However, people often overlook the fact that it wields the power to shape their perspectives on discrete issues. Therefore, it is important to critically analyze items of popular culture to evaluate the ways in which products such as books, cinema, and music represent prevailing social difficulties. By using It Ends with Us as its corpus and the peripheral characters as its focus, this study aimed to bridge the gaps in the scholarly discourse about the portrayal of domestic violence in literature. Despite arguments by many specialists about the importance of informal networks in helping victims of domestic abuse, only a few researchers have investigated representations of such informal support systems in popular fiction. Future research on this theme should scrutinize other novels and attempt to further fill this research lacuna.

\section{Acknowledgment}

We would like to thank Universitas Indonesia for providing the academic platform for us to conduct our research and for the opportunity to share our findings at an international conference at the Faculty of Humanities, Universitas Indonesia.

\section{References}

[1] Christina. (2016, August 8). It ends with us [Review of the book It ends with us]. Girl in the Pages. Retrieved from https:/girlinthepages.com/2016/08/08/it-ends-with-us/

[2] Hoover, C. (2016). It Ends With Us. New York: Atria Books.

[3] CNN Library. (2018, June 1). Domestic (intimate partner) violence fast fact. Retrieved from https://edition.cnn.com/2013/12/06/us/domestic-intimate-partnerviolence-fast-facts/index.html

[4] Best romance. (2016). Retrieved from https://www.goodreads.com/choiceawards/best-romance-books-2016

[5] Aestas. (2016, July 31). Book review-It ends with us [Review of the book It ends with us]. Aestas Book Blog. Retrieved from https://aestasbookblog.com/it-ends-with-us-review/

[6] Anderson, J.F., \& Kras, K. (2007). Revisiting Albert Bandura's social learning theory to better understand and assist victims of intimate personal violence. Women \& Criminal Justice, 17(1), 99-124. DOI: 10.1300/J012v17n01_05

[7] Kohlman, S., Baig, A., Balice, G., DiRubbo, C., Placencia, L., Skale, K., ... Aquino, S. (2014). Contribution of media to the normalization and perpetuation of domestic violence. Austin Journal of Psychiatry and Behavioral Sciences, 1(4). Retrieved from, http://austinpublishinggroup.com/

[8] Parker, I. (2015). A link in the chain: The role of friends and family in tackling domestic abuse. Retrieved from https://www.citizensadvice.org.uk/Global/CitizensAdvice/Crime\%20a nd\%20Justice\%20Publications/Linkinthechain.pdf

[9] Akiona, J. (2015). Dependent women and the male gaze in fictional domestic violence films. Hohonu, 13. Retrieved from https://hilo.hawaii.edu/campuscenter/hohonu/volumes/documents/De pendentWomenandtheMaleGazeinFictionalDomesticViolenceFilmsJe ssicaAkiona.pdf

[10] Salmi, A. (2013). Abusive behavior: An analysis of Edward Cullen in Stephenie Meyer's Twilight. Retrieved from, http://www.divaportal.org/smash/record.jsf?pid=diva2:705906

[11] Sidortsova, S. (2018). Big little representations: How Hollywood shapes our views of domestic violence. Retrieved from https://www.mtu.edu/news/stories/2018/march/big-little- 
representations-how-hollywood-shapes-our-views-of-domesticviolence.html

[12] Flood, M., \& Pease, B. (2009). Factor influencing attitudes to violence against women. Trauma, Violence, and Abuse, 10(2), 125142, DOI 10.1177/1524838009334131

[13] Flood, M., Pease, B., Taylor, N., \& Webster, K. (2009). Reshaping attitudes toward violence against women. In Stark, E., \& Buzawa, E. S. (Eds.), Violence against Women in Families and Relationships (pp. 177-198). Santa Barbara, CA: Praeger. Retrieved from https://www.researchgate.net/publication/234028320_Reshaping_Atti tudes_toward_Violence_against_Women

[14] Nurgiyantoro, B. (2015). Teori Pengkajian Fiksi. Yogyakarta: Gajah Mada University Press

[15] Schippers, M. (2007). Recovering the feminine other: Masculinity, femininity, and gender hegemony. Theory and Society, 36 (1), pp 85102. DOI 10.1007/s11186-007-9022-4.

[16] Fernandéz, M. (2006). Cultural beliefs and domestic violence. Violence and Exploitation Against Women and Girls. 1087 (1), 250 260. DOI: https://doi.org/10.1196/annals.1385.005

[17] Boonzainer, F. \& C. De La Rey. (2003). He's a man and I'm a woman: cultural consructions of masculinity and femininity in South African women's narratives of violence. Violence Against Women 9, 1003-1029.

[18] Yamawaki, N., Ochoa-Shipp, M., Pulsipher, C., Harlos, A., \& Swindler, S., (2012) Perceptions of domestic violence: The effect of domestic violence myths, victim's relationship with her abuser, and the decision to return to her abuser. Journal of Interpersonal Violence, 27(16), 3195-3212. DOI 10.1177/086260512441253Writer's Handbook. Mill Valley, CA: University Science, 1989.

[19] Okun, L. (1866). Woman abuse: Facts replacing myths. Albany: State University of New York Press.
[20] Filipovic, J. (2018). 14 misconceptions about domestic violence. Domesticshelters.org. $\quad$ Retrieved from https://www.domesticshelters.org/articles/domestic-violence-op-edcolumn/14-misconceptions-about-domestic-violence

[21] Kim, J., \& Gray, K. A. (2008). Leave or stay? Battered women's decision after intimate partner violence. Journal of Interpersonal Violence, 23, 1465-1482. DOI: 10.1177/0886260508314307

[22] Vohra, M. (2016). The decision-making processes involved in ending intimate partner violence among indian female immigrants (Order No. 10192746). Available from ProQuest Dissertations \& Theses Global; Psychology Database. (1881838236). Retrieved from https://remotelib.ui.ac.id:2155/docview/1881838236?accountid=17242

[23] Kaufman, J., \& Zigler, E. (1993). The intergenerational transmission of abuse is overstated. Current Controversies on Family Violence. Newbury Park, CA: Sage Publications.

[24] Renner, L. M., \& Slack, S. L., (2004). Intimate partner violence and child maltreatment: Understanding co-occurrence and $\begin{array}{lll}\text { intergenerational connections. } & \text { Retrieved }\end{array}$ https://www.irp.wisc.edu/publications/dps/pdfs/dp127804.pdf

[25] Bemiller, M. L., \& Schneider, R. Z. (2010). It's not just a joke. Sociological Spectrum, 30(4), 459-479. doi:10.1080/02732171003641040

[26] Hammarén, N., \& Johansson, T. (2014). Homosociality: In between power and intimacy. SAGE Open, 4(1). doi:10.1177/2158244013518057

[27] Flood, M. (2008). Men, sex, and homosociality: How bonds between men shape their sexual relations with women. Men and Masculinities, 10, 339-359. DOI: 10.1177/1097184X06287761

[28] Rodan+Fields Company. (n.d). Retrieved from, https://www.rodanandfields.com/pages/amp-md-roller-intensiverenewing-serum-lp 